\title{
SUBJETIVIDAD Y MODALIDAD LINGÜÍSTICA
}

\author{
María Encarnación Pérez Sedeño \\ Catedrática de Lengua y Literatura españolas \\ I.E.S. Fuerte de Cortadura, Cádiz
}

\section{RESUMEN}

La finalidad de este trabajo es mostrar que el fenómeno conocido por modalidad no debe ser identificado con ninguna clase de palabras gramaticales.

El tratamiento que las gramáticas del español han dado al fenómeno, presentado como una categoría a la que se aplican las condiciones necesarias y suficientes del sentido de la palabra, esto es, la determinación de la verdad o falsedad del predicado por parte del sujeto, no se corresponde con el modelo de comunicación comúnmente aceptado hoy. Ese tratamiento no contempla el carácter interactivo de la comunicación lingüística y considera sólo el contenido proposicional de los enunciados.

El concepto de modalidad ha de inferirse, en cambio, de los mecanismos lingüísticos que el hablante elige en las diferentes situaciones comunicativas. Estos mecanismos, que en determinados discursos pueden no ser relevantes de una determinada modalidad, pueden serlo en otros. El carácter intersubjetivo de la comunicación debe ser, en la perspectiva enunciativa, el punto de partida del análisis de los elementos que en cada discurso se activan como huellas de la subjetividad del hablante por el hecho de ser elegidos libremente por él. La complejidad y variedad de estos elementos lingüísticos difiere de unos discursos a otros de acuerdo también con la formación discursiva del enunciador. 


\section{INTRODUCCIÓN}

A partir de la década de los cincuenta, en el seno de la Filosofía del Lenguaje (Austin, 1955) y en Lingüística (Benveniste,1950), surgen estudios agrupados, grosso modo, en dos grandes corrientes: la corriente Pragmática y la corriente Enunciativa, que tienen en cuenta el acto mismo de producción de lenguaje, los sujetos que intervienen en la comunicación y la situación en que se produce (contexto en sentido amplio).

Pero la relación que se establece entre el sistema lingüístico y el uso que los hablantes hacemos de él en la vida social, es bastante compleja. Por eso, desde el momento en que la Lingüística empieza a plantearse desde una perspectiva funcional la consideración del discurso, el uso lingüístico contextualizado, es decir, cómo las formas lingüísticas se ponen en funcionamiento para construir formas de comunicación y de representación del mundo, real o imaginario, el papel del hablante y su relación con el interlocutor cobra un gran interés.

La elección de estas formas por parte de los hablantes, sujeta o no a un control consciente, se realiza de acuerdo con unos parámetros contextuales que incluyen la situación, la intención comunicativa y las características de los destinatarios, entre otros. Estos parámetros, de tipo cognitivo (Sperber y Wilson, Lakoff) y sociocultural (Ducrot, Grice), son dinámicos y están sujetos a revisión y cambios.

La referencia en el discurso a un lugar de enunciación que permite identificar lo que a partir de L'archéologie du savoir de M. Foucault (1969) se llama "formación discursiva», rescata al sujeto del ámbito puramente estilístico en el que se le había instalado. Esta formación discursiva determina el status del enunciador, la posición que adopta institucionalmente, entendiendo por institución el dispositivo que delimita el ejercicio de la función enunciativa. Las marcas o huellas de subjetividad que aparecen en los discursos, no remiten pues a un individuo concreto, sino a un tipo de enunciador inscrito en una tradición cultural determinada.

Así, las huellas de la subjetividad del hablante quedan en los enunciados como testimonio de ese contexto en sentido amplio del que hemos hablado, sin que ello implique merma en la libertad de elección de las formas linguísticas en el tipo de discurso que realiza.

La subjetividad tomada en este sentido adquiere en el lenguaje un status científico insuficientemente desarrollado hasta ahora en las teorías linguiísticas, y se manifiesta como un hecho discursivo, explicativo de una manera de conceptualizar. 


\section{SUBJETIVIDAD Y MODALIDAD}

La subjetividad lingüística tiene su fundamento en la intersubjetividad que es lo específico del lenguaje (Benveniste,1968), y se comprende a la luz de dos hechos fundamentales: la enunciación y el carácter inferencial de nuestra comunicación (Moescheler-Réboul, 1994).

A partir de la enunciación y de las inferencias que los hablantes-oyentes somos capaces de realizar, y que son para la lingüística enunciativa generales y compartidas por los interlocutores, se pueden estudiar desde otra perspectiva fenómenos como el de los llamados enunciados realizativos, la interpretación de determinados conectores, adverbios extraoracionales y determinados usos de la negación, así como la modalidad. Todos ellos son índices de la manera en que el hablante se apropia de la lengua y la convierte en discurso.

Por otro lado, propiedades de la comunicación como la reflexividad, la simetría y la transitividad (Kerbrat Orecchioni, 1989) permiten captar cómo se manifiesta esa intersubjetividad en la que se muestra la peculiaridad del sujeto. Por reflexividad se entiende el hecho de que el emisor del mensaje es al mismo tiempo su primer receptor; por simetría se entiende cómo todo receptor actúa al mismo tiempo como un emisor en potencia; por último, la transitividad es la propiedad que permite transmitir a un receptor una información que a su vez puede ser transmitida a otro receptor sin que el primero haya experimentado su validez, es decir, la información puede transmitirse a distintos sujetos cada uno de los cuales puede ir modificándola.

A través de estos hechos se puede comprender el fenómeno conocido como modalidad. En el proceso que es el discurso, es en el que el enunciador va a manifestarse de una manera determinada, va a dejar su impronta, sin perder de vista que este enunciador está siempre inscrito en una tradición cultural determinada como hemos mencionado antes. El enunciador interactúa con el receptor, quien a la vez puede ser sujeto de otra enunciación respecto de otro receptor. La intersubjetividad señalada por Benveniste, no dualidad, pone de relieve siempre el papel activo del sujeto de la enunciación. Esa actividad se manifiesta con unas marcas lingüísticas variadas que es lo que constituye el hecho linguíístico modal.

Pero para que modalidad no se confunda con expresividad, como puntualiza Cervoni (1987), y tenga pertinencia en lingüística, hay que delimitar como modalidad lo que se manifiesta como elección, consciente o no, del enunciador.

El propósito de este trabajo es mostrar que la utilización que se hace en las gramáticas del español de los términos modalidad y modo, responden a una concepción tradicional de lo que es un concepto y de la manera por la que 
se establecen las categorías gramaticales, y a veces olvidan este carácter interactivo de la comunicación cuyo fundamento son los sujetos activos de la misma, que eligen formas lingüísticas determinadas para comunicarse. Es decir, la modalidad se presenta en estas gramáticas como una característica oracional y no enunciativa, y parten de una definición intensional y extensional del término, sin reparar en la función efectiva que el concepto desempeña en la comunicación.

Nuestra propuesta es la comprensión del fenómeno modal desde una perspectiva enunciativa en la que los criterios lógicos no limiten el papel del sujeto al contenido proposicional del enunciado, sino que se comprenda como fenómeno discursivo en el que el hablante refleja su posición y formación discursiva a través de todos los elementos lingüísticos que tiene a su disposición, no categorizables en términos de condiciones necesarias y suficientes. Restituir al término el valor de categoría no definida y analizar la polisemia del mismo, no implica ni vaguedad ni imprecisión.

El sentido del término modalidad que en los estudios tradicionales desde la filosofía se ha ido filtrando en linguística, ha oscurecido el papel que desempeña el sujeto en la explicación misma del fenómeno modal. La revisión del término así como la del concepto al que remite, es nuestro propósito.

Tomaremos en consideración los criterios que se han usado para definirlo en una muestra representativa de cuatro gramáticas del español. Finalmente indicaremos cuáles son los criterios que, desde esa perspectiva discursiva, pueden ser utilizados para analizar la modalidad, estableciéndose así el término como una categoría sin límites determinados ni cerrados.

\section{EL TÉRMINO MODALIDAD}

Frecuentemente al usar el término modalidad se utiliza como equivalente de modo para hacer referencia a la relación que se establece entre el locutor o hablante y el oyente o interlocutor, pero teniendo siempre presente el contenido proposicional de su enunciado con relación a la verdad o falsedad del mismo. En ese sentido el término tradicionalmente se emplea para una clasificación de la oración en tres grupos: aseverativas o declarativas, interrogativas e imperativas.

Por otro lado el término modo parece tener relación con modus, la actitud que manifiesta el hablante frente al contenido de lo que dice o dictum (contenido representado).

Junto a los términos tradicionales de modalidad y modo, ha surgido en la lingüística enunciativa el término modalización, también con matices signifi- 
cativos distintos (Jean Dubois, 1973). Como sinónimo de modo, «la modalidad define el estatuto de la oración" ' pues el modo ha estado como categoría gramatical asociada generalmente al verbo. El término modalización se refiere en cambio a la adhesión que el hablante manifiesta respecto a su enunciado de manera general a lo largo del discurso como conjunto (conceptos como distancia, transparencia y tensión explican esa modalización).

\section{El CONCEPTO DE MODALIDAD}

Para Benveniste (1974) la modalidad «ne fait pas partie des catégories nécessaires et constitutives du paradigme verbal». Su afirmación está vigente aún como mostraremos a lo largo de esta exposición.

$\mathrm{Si}$ aceptamos que categorizar es una operación mental que consiste en agrupar cosas diferentes, operación por la que superar entidades individuales (sean concretas o abstractas) y llegar a una estructuración conceptual (Kleiber, 1995), tendremos que preguntarnos sobre qué bases agrupamos la manifestación del sujeto recogida bajo la denominación de modo o modalidad.

Si como hacen las teorías tradicionales sobre el concepto, admitimos que este contiene las propiedades poseídas por los individuos que pertenecen a una clase que es la extensión del concepto, y que estas propiedades determinan el conjunto de condiciones necesarias y suficientes para la aplicación del concepto, tendremos que establecer los criterios que presiden el agrupamiento de las mismas. Esta concepción responde a la concepción clásica del sentido de una palabra, sentido denotativo o referencial. La semántica estructural también acepta el modelo de las condiciones necesarias y suficientes pero desde un punto de vista operativo y funcional, liberándose del sentido referencial de la palabra. Así, la categoría modo se establece con relación a las de tiempo y aspecto de la acción verbal.

Ahora bien, si admitimos que categorizar ya no es descubrir una regla de clasificación, sino señalar covariaciones y similitudes globales y la formación de prototipos de referencia, tal como hace la llamada corriente experiencialista, describiremos la organización interna y externa de la categoría en relación con su funcionalidad. Si bien los conceptos abstractos como modo, comparativamente con los conceptos concretos de nivel básico (clases naturales) están menos estudiados, se presentan como categorías con una extensión no definida. Al concepto y categoría modo le corresponderán una

1 J. Dubols y otros, págs. 425 y 428 de Diccionario de Lingüistica, Madrid: Alianza Editorial. 
variedad de definiciones o representaciones semánticas. Lo que constituye el indicador de la categoría ya no es el concepto o su equivalente en el plano semántico, la acepción o el sentido, sino que es la unidad léxica, de la que analizaremos su polisemia.

\section{El concepto de modo en las gramáticas del español. El modo como categoría.}

En la Gramática de Nebrija el modo siempre hace referencia a un accidente del verbo el cual «es aquello por lo que se distinguen ciertas maneras de significar"; indicativo es el modo o manera de «indicar o mostrar»; subjuntivo es aquel por el que juntamos un verbo con otro «porque subjungere es aiuntar» etc. ${ }^{2}$

Andrés Bello en su Gramática de la Lengua, aunque trata el fenómeno desde el aspecto puramente gramatical de la rección verbal, en el apéndice del editor al capítulo XXI dice en 222 «Se llama Modo la forma que toma el verbo para indicar operaciones del entendimiento o emociones del ánimo. Cuando se dice dudo, deseo, no es la forma del verbo sino la raíz lo que significa la duda, el deseo. Pero cuando se dice dudo que venga, ojalá que venga, ven, la forma, la inflexión que damos al verbo venir conviene a la incertidumbre, a la duda, al deseo, y da a la proposición ese valor particular que se llama modo".

El modo ya no es solo una característica de la flexión verbal, es un valor de la proposición, y aunque no especifique en qué consiste exactamente ese valor, sí podemos captar en la alusión a la actitud del hablante el sentido que imprime este a la proposición.

El Esbozo de una Nueva Gramática de la Lengua Española, (1978) de la Real Academia trata la modalidad oracional distinguiendo en ella el dictum o contenido representativo, esto es, lo que se dice en cada oración, del modus, la manera de decir o actitud subjetiva del hablante respecto a ese contenido. Hay que señalar que identifica el contenido representativo de la oración con el contenido representativo del verbo.

La modalidad aparece en esta obra como una categoría semántica que tiene que ver con el contenido proposicional. De manera que la oposición realidad-irrealidad es la que los modos indicativo y subjuntivo marcan.

La Gramática Española de Alcina y Blecua, (1975), solamente trata la modalidad en el apartado de la sintaxis compuesta, al describir las proposicio-

2 Nebrija, Elıo Antonio de, pág 114 en Gramática de la légua castellana, Salamanca. Edición facsímil V Centenario. Instituto de Cultura hispánica 1992. 
nes completivas de sujeto y de complemento directo. Allí recoge la definición tradicional de modus, «el modo como el sujeto encara lo que la proposición comunica (dictum) [...] la actitud del sujeto la refleja el verbo dominante, mientras la proposición recoge el contenido de la oración que es valorada, deseada, pensada, etc.» (8.1.11).

Al igual que la Gramática de la Academia, interpreta el subjuntivo como forma de la irrealidad frente al indicativo, que sirve para enunciar lo cierto, verdadero o falso, real o supuesto. Los criterios lógicos siguen estando en la base de estas afirmaciones.

No obstante cuando esta Gramática caracteriza las oraciones llamadas tradicionalmente adverbiales de modo, en las que se involucran los conceptos de modo y comparación, llama valorativas a las caracterizadas por un intensivo (adjetivo de un sustantivo o sustantivo que expresa cantidad, adverbio referido a otro adverbio, etc.), cuyo sentido desarrolla la construcción introducida por como (8.2.1.) También en las llamadas frases verbales (perífrasis), al hablar de la bipredicación de estas, señala el carácter obligativo que consiguen las perífrasis con verbos tener y haber, más un que, viejo relativo neutralizado, y el infinitivo; o bien con deber + infinitivo, construcción que a veces se tiñe de un matiz de aproximación (en ese caso, deber + de + infinitivo). Añade a este tipo de frases modales las construidas con soler y poder + infinitivo.

Parece pues que a esta Gramática sólo le interesa, en el análisis descriptivo de los enunciados del discurso, reparar en la actitud del hablante respecto al contenido del enunciado, no respecto al oyente. No obstante, a pesar de su defensa del criterio morfosintáctico, el criterio semántico aparece ineludiblemente en la clasificación de las perífrasis verbales, en la caracterización los modos verbales, y en la descripción de las oraciones compuestas modales.

Otras referencias modales son las de los adverbios de modo (4.9.1.1), y a las expresiones de modo (6.2.5). En el primer caso se menciona la modificación que impone el adverbio al verbo, al adjetivo o a otro adverbio; en el segundo caso la afectación que determinadas preposiciones imponen a nombres o adjetivos con los que se asocian indicando expresión de modo (es el caso de de, a, por, con, en: «a gatas, de firme, por ventura, con prudencia, en serio»).

La Gramática descriptiva de la Lengua Española (1999), siguiendo la tradición europea de análisis linguístico, recoge la distinción entre modalidad de la enunciación y modalidad del enunciado y considera que la distinción es útil porque en el análisis de determinadas categorías gramaticales «los límites de estas se acomodan exclusivamente a uno de los dos tipos de modalidad», y cita como ejemplo de ello el que en español la interrogación constituye una modalidad de la enunciación frente a la declaración. No obstante «con relativa fre- 
cuencia encontramos que una determinada categoría lingüística modal implica tanto a la enunciación como al enunciado» ${ }^{3}$

Aprovecha esta gramática la distinción hecha por los lógicos entre modalidad epistémica, vinculada a las nociones de conocimiento y creencia, que expresa el grado de compromiso que el hablante asume respecto a la verdad de la proposición contenida en el enunciado; y modalidad deóntica, que supone una formulación de estas condiciones como pertenecientes a un sistema normativo en el que actúa el agente de la proposición o directamente el hablante. Pero ya menciona que cada uno de los dos tipos de modalidad puede recibir su expresión mediante recursos linguísticos diversos: la deóntica a través de la entonación, la sintaxis, o la variación en el modo verbal; la epistémica a través de adverbios, adjetivos, verbos modales, y también variación en el modo del verbo.

Esta misma gramática, cuando habla de los marcadores discursivos (63. 1 . 6), «aquellos signos que no contribuyen directamente al significado conceptual de los enunciados sino que orientan y ordenan las inferencias que cabe obtener de ellos» ${ }^{4}$, cita los marcadores de modalidad deóntica.

Asimismo en 60.1.1.2, cuando se habla de los tipos básicos de los actos de habla en relación con la teoría de los prototipos, se relacionan estos con la modalidad. Se propone una clasificación de los tipos de actos de habla correspondientes a los tipos de oraciones: acto asertivo / tipo declarativo, acto de pregunta / tipo interrogativo, acto de orden / tipo imperativo, acto de expresión de emoción / tipo exclamativo. Pero según esto, otros tipos oracionales como la probabilidad, la duda y el deseo, no aparecen porque son fenómenos que permiten evitar el compromiso epistémico del hablante. No siempre hay correspondencia entre tipo de oración y tipo de acto de habla, por ejemplo, en los llamados actos de habla indirectos. Es decir, en esta concepción se sigue considerando en la modalidad el contenido proposicional del enunciado.

Todas las gramáticas mencionadas tienen una cosa en común: la atención que prestan al verbo del dictum con relación al significado del verbo del modus, en función de los criterios lógico-semánticos usados para su comprensión.

Como ya hemos dicho, desde las gramáticas medievales, herederas de las griegas y latinas, se ha tendido a ver en los enunciados dos aspectos constitutivos: el contenido proposicional y la modalidad. Se aplicó el término dictum

3 Gramática descriptiva de la lengua española, pág. 323 Madrid: Espasa 1999.

4 Gramática descriptiva de la lengua española, pág. 4058 Madrid: Espasa 1999. 
para el primero, y el término modus para el segundo. De manera que la modalidad se entiende sólo en relación al contenido proposicional.

El modus lo definen los lógicos como la determinación de algo, efectuada por un adjetivo nominal que modifica a un sustantivo; o por un adverbio que determina a un verbo.

El criterio para establecer la determinación de la proposición modal la establecen los lógicos tomando en cuenta la verdad del contenido de la proposición, el conocimiento o la creencia del hablante respecto a esa verdad de la proposición, o las condiciones en que se establece la verdad del predicado como pertenecientes a un sistema normativo. Se distinguen así lo que se llaman modalidades aléticas, epistémicas y deónticas en base a las cuales quedan definidos los modos que expresa el verbo: indicativo, subjuntivo e imperativo.

La semántica léxica de Greimas, después de evolucionar hacia una perspectiva semiológica, define la modalidad como «la modification du predicat par le sujet» (Langages, septiembre 1976), es decir, como «un acte de langage... qui n'est manifesté que dans et par ses résultats en tant qu'énoncé» y la única manera de hablar del acto de habla en el que el sujeto modifica al predicado, consiste en darle una representación semántica canónica. El modo es pues una categoría semántica que se reconstruye a partir del enunciado como acto de habla.Y para él esa categoría semántica se articula sobre el «poder» y el «saber».

Bernard Pottier (Langages, 1973) se apoya en expresiones como deber, poder, saber y querer, que son esenciales en la expresión de la subjetividad en el mensaje lingüístico, para clasificar así las distintas modalidades en función del papel que desempeñe la primera persona. Aunque distingue también con criterios lógicos la modalidad epistémica, diferenciará no obstante la modalidad factitiva, orientada hacia la acción, y la axiológica que tiene que ver con el juicio que hacen los hablantes sobre lo que se formula.

La semántica oracional, no considera el modo como una categoría sintáctico-semántica con significado propio, sino como un cambio morfológico que experimenta un verbo de manera automática en función de su posición subordinada (María Luisa Rivero, 1977).

Hemos visto hasta aquí cómo la unidad léxica modo indica una categoría morfosintáctica y semántica a la que se le aplican las condiciones necesarias y suficientes del sentido de la palabra, esto es la determinación de la verdad o falsedad del predicado por parte del sujeto. A partir de una definición analítica del significado, independientemente de la experiencia, aplicamos el concepto.

Desde la teoría del prototipo hemos visto, en cambio, que la palabra modo indica una categoría no definida. 
El uso que hace la pragmática del término modo se basa en una dimensión funcional: el concepto deriva de un acto y está sujeto a unas condiciones de realización y a unas consecuencias. Las situaciones comunicativas concretas nos permiten inferirlo, por lo que el contexto desempeña un papel explicativo del uso que hacemos de él; la inferencia no es a priori sino a posteriori, a partir de la experiencia.

\section{La modalidad en la Pragmática}

Herman Parret censura que las teorías gramaticales clásicas definan la modalidad al nivel del léxico: «la force sémantique des modalités et leurs distributions syntaxiques s'identifient alors au sens et au comportement syntaxique des verbes modaux comme pouvoir, devoir, savoir, vouloir» (Langages n. ${ }^{\circ} 43$ ). Él por su parte defiende otros elementos que el autor llama «periféricos» con relación a esos elementos «nucleares» sobre los que ha recaído tradicionalmente la modalidad. Estos radican en secuencias morfológicas o incluso en la entonación.

El autor plantea la posibilidad de diferenciar entre actitudes proposicionales y actitudes o actos ilocucionarios, y establecer así otra consideración de la modalidad. El acto proposicional es un acto de referencia y de predicación, donde las consideraciones epistemológicas y ontológicas tienen cabida, mientras que el acto ilocucionario, está constituido por una cierta realidad y motivado por la producción y reconocimiento de intenciones no ocultas sino clasificables y convencionalizadas. En este sentido se dice que los realizativos son operadores modales porque afectan y modifican globalmente el contenido semántico de los enunciados. La tipología de las modalidades se establece a partir de la especificidad de las reglas que gobiernan la actitud ilocucionaria en cuestión, de las convenciones linguísticas de los enunciados, y de las convenciones extralingüísticas de las situaciones comunicativas.

En opinión de Herman Parret hay otro tipo de modalidad que se puede superponer a las anteriormente expuestas; él la califica como axiológica.

Desde la corriente enunciativa autores como Cervoni (1987) diferencian, en cambio, modalidad de performatividad. Dice este autor que son fenómenos autónomos pero separados (enunciados realizativos como je m'excuse, no presentan rasgos modales y otros con auxiliares modales como $a$ dî, en «aprés le scandale Pierre a dû s' exiler», no indican performatividad alguna). El término modalización alude en este autor al fenómeno general del que forma parte la modalidad y define como «le reflet, dans le langage, du fait que tout ce que l'homme peut être, sentir, penser, dire et faire». 
Interesada como ya hemos dicho por la repercusión que la actividad del hablante tiene en el enunciado y en el oyente, analiza el fenómeno de la modalidad considerando fundamentalmente la huella que en los enunciados deja el sujeto.

Ahora bien, la modalidad es un fenómeno relacionado con el sujeto hablante en la «instance du discours». En este sentido, siguiendo a Jakobson, se ha distinguido entre modalidades de enunciación y modalidades de enunciado (Meunier 1974, Otaola Olano, 1988).

Hay autores como M. Victoria Escandell (1999) que opinan que la distinción no es pertinente aunque sea provechosa. Dice ella que si la distinción es útil para analizar determinadas categorías gramaticales que se acomodan más a un tipo $\mathrm{u}$ otro de modalidad, no es menos cierto que determinadas categorías lingüísticas modales implican tanto la enunciación como el enunciado. Es el caso de los enunciados interrogativos que desde el punto de vista semántico son «enunciados abiertos» o «funciones proposicionales», y no pueden ser evaluados en términos de verdad o falsedad (el subrayado es nuestro), y desde el punto de vista de la enunciación no pueden considerarse oraciones, en muchos casos porque no tienen estructura de tales.

Por nuestra parte queremos señalar una vez más que la categorización gramatical del fenómeno sólo es posible aplicando criterios lógicos y semánticos. Desde el criterio funcional no es una categoría definida.

El enfoque enunciativo en el análisis de la modalidad debe considerar el sujeto como elemento activo que presenta una actitud, no sólo respecto a la verdad o falsedad del contenido de la proposición del enunciado, sino respecto a la manera en que el hablante sitúa el enunciado con relación a juicios de valor como lo útil, lo bueno, etc.

Desde esta perspectiva surgen ciertas matizaciones al enfoque lógico de la modalidad alética. Ch. Bally (1950), por ejemplo, señala que a pesar de la diferenciación entre dictum y modus, este último no es una característica lógica del dictum, Bally incluye en el dictum todo elemento indicador de algún tipo de expresividad del hablante, con independencia del procedimiento que emplee en su formulación.

En la misma línea hace J. Cervoni la observación de que el valor de verdad de la proposición se ve afectado a veces por los cuantificadores, adverbios de tiempo y de lugar. Da como ejemplo Pierre est toujours odieux, o Pierre est quelques fois odieux, donde las marcas temporales modifican la verdad de Pierre est odieux. Propone que en un tratamiento «extensivo» de la modalidad se tomen en consideración las modalidades que él llama «cuantitativas», «temporales» y «espaciales».

J. Cervoni relaciona también la modalidad deóntica de la lógica con la que él llama «evaluativa». Al ser el rasgo esencial de su definición el de implicar 
una referencia a las normas, no hay por qué limitarse a las nociones establecidas por los lógicos, sino que se podrán integrar en esta clase de modalidad expresiones como adverbios de manera (Sócrates corre rápidamente), así como un gran número de adjetivos (delicioso, importante), o de verbos (apreciar), etc., según la norma sea social, ética, estética, etc. La modalidad llamada «axiológica» constituye una subclase de la modalidad deóntica.

El lingüista debe considerar cómo se manifiesta la modalidad en la morfología, la sintaxis y el léxico y no hacerla coincidir necesariamente con las modalidades lógicas (Cervoni, 1987).

\section{CONCLUSIONES}

Hemos visto que la modalidad como categoría aparece en las gramáticas españolas adscrita fundamentalmente al verbo como núcleo de la proposición que expresa el llamado modus. Los criterios lógico-semánticos son los que utilizan estas gramáticas para el establecimiento de la categoría.

La Corriente Pragmática reivindica el papel de los realizativos en el contenido semántico de los enunciados, a la vez que niega que el fenómeno modal sea un fenómeno exclusivamente léxico.

La Corriente Enunciativa propone no hacer coincidir necesariamente con las modalidades lógicas las modalidades lingüísticas, pero sigue situando estas modalidades lógicas en la base de la tipología modal explícita, frente a las modalidades apreciativas y expresivas (Cervoni).

La necesidad de categorizar siguiendo el modelo tradicional ha originado las posturas diferentes que se han venido señalando como excluyentes (por ejemplo performatividad versus modalidad)

Por el uso que se hace del término, hemos visto que remite a sentidos diversos. Sin embargo, intuitivamente, percibimos que lo que la modalidad indica es la elección que los hablantes hacemos para marcar nuesta posición ante nuestra representación del mundo y ante la relación interpersonal que establecemos con nuestros interlocutores.

$\mathrm{Si}$, como proponemos, el análisis de la modalidad de un discurso determinado se hace a través de unos parámetros contextuales que incluyan la referencia a valores sociales, culturales y textuales, podremos analizar cómo se manifiesta la elección que los hablantes hacemos. Este análisis debe considerar la predicación de los enunciados (modalidad proposicional, lógica), la performatividad, la tematización, la cuantificación, e incluso la metaforización que presente el discurso. Por supuesto el lingüista tiene para ello a su disposición los elementos léxicos y morfosintácticos así como fónicos que los enunciados le 
ofrecen. Los criterios aplicados al análisis del fenómeno modal en el discurso pueden variar de un discurso a otro.

Así, en el análisis discursivo es donde cobra sentido la manera que tiene el hablante de concebir el mundo, bien como representación bien como campo de relación y actuación.

$\mathrm{Si}$ admitimos que las categorías y conceptos son entidades mentales débilmente organizadas, con poco o nada que ver con las condiciones necesarias y suficientes que la concepción tradicional les atribuye, admitiremos el papel explicativo que aporta el contexto, en la variabilidad y flexibilidad de las propias categorías.

Defendemos pues el fenómeno modal como fenómeno discursivo en el que han de tenerse en cuenta los valores socioculturales de la tradición en que se inscribe el enunciador y, considerado este aspecto, defendemos un análisis en el que quepan tanto los criterios lógico-semánticos como pragmáticos, según lo requiera el propio discurso.

La modalidad no es una categoría o concepto que se pueda definir intensional y extensionalmente, identificable con ninguna clase de palabras gramaticales. Al contrario, es un hecho enunciativo que pertenece al discurso y que adopta expresiones diferentes en función de las intenciones comunicativas del enunciador. Es la subjetividad de este la que manifestará en su elección los valores que le identifiquen con su formación discursiva, tanto en la enunciación como en el propio enunciado.

\section{REFERENCIAS Bibliográficas}

Austin, J. L. (1962) Cómo hacer cosas con las palabras, Barcelona, Paidós, 1982. BALLY, CH. (1950) Lingüistique Générale et Lingüistique Française, Berne, A. Franke S.A.

BEAUGRANDE-DRESSLER, R. et W. (1997) Introducción a la lingüistica del texto, traducción española de Sebastián Bonilla, Barcelona, Ariel.

Bello, A. (1850) Gramática de la lengua castellana destinada al uso de los americanos. Edición Crítica de Ramón Trujillo, 1981. Tenerife, Cabildo Insular.

Benveniste, E. (1968) Problèmes de Lingüistique Générale, Vol. I, Paris, Gallimard, p. 260.

Cervoni, J. (1987) L'énontiation, Paris, Presses Universitaires de France.

COQuet, J. C. (1976) «Les modalités du discours», Langages, 43, págs. 64-77.

CuenCA-HiLferty. M. J. y J. (1999) Introducción a la lingüística Cognitiva, BarceIona. Ariel.

Dubols, J. (1979) Diccionario de Lingüística. Traducción española de I. Ortega y A. Domínguez, Madrid, Alianza Editorial. 
DuCrot, O. (1984) Le dire et le dit, Paris, Minuit.

ESCANDELL, V., "Los enunciados interrogativos, aspectos semánticos y pragmáticos» (6.1.1) en Real Academia de la Lengua (1999) Gramática descriptiva de la Lengua Española, dirigida por Ignacio Bosque y Violeta de Monte, Madrid, Espasa.

FouCAULt, M. (1969) L'archéologie du savoir, Paris, Gallimard.

Greimas, A. J. (1966) Sémantique Structurale, Paris, Librairie Larousse.

Greimas, A. J. (1976) «Pour une théorie des modalités», Langages, 43, págs. 90-107.

GricE, P. (1975), «Lógica y conversación», en L. Valdés (ed.), La búsqueda del significado, Madrid, Tecnos/Universidad de Murcia, 1991.

Kerbrat-OrecChioni (1989) L'Énontiation. De la subjetivité dans le langage. París, Armand Collin.

KLEIBER, G. (1995) La semántica de los prototipos. Categorías y sentido léxico. Traducción española de Antonio Rodríguez Rodríguez. Madrid, Visor.

LAKOFF, G. y M., Mark (1980) Metáforas de la vida cotidiana, Madrid, Cátedra, 1991.

MoesCheller-Réboul, J. et A. (1994) Dictionnaire Encyclopédique de Pragmatique, Paris, Éditions du Seuil.

NebriJa, E. A. (1492) Gramática de la Légua Castellana. Salamanca MCCCCICII. Madrid, edición del Instituto de Cultura Hiapánica, V Centenario.

OTAOLA, C. (1988) «La modalidad (con especial referencia a la lengua española)». En Revista de Filología Española, tomo LXVIII, fasc. $10^{\circ}$ y $2 .^{\circ}$

PARRET, H. (1976) «La pragmatique des modalités», Langages, 43, págs. 43-47.

POTTIER, B. (1973) «Sur la formulation des modalités en lingüistique» Langages, 43 , págs. 39-46.

Rivero, M. L. (1977) Estudios de gramática generativa del español. Madrid, Cátedra. REAl ACADEMIA EsPañola (1978) Esbozo de una nueva Gramática de la Lengua Española, Madrid, Real Academia.

ReAl ACAdEmia Española (1999) Gramática descriptiva de la Lengua Española. dirigida por Ignacio Bosque y Violeta de Monte, Madrid, Espasa.

SPERBER, D. y D. WILsON (1986) La Relevancia. Madrid, Visor (1991). 